\title{
Organizational Justice and Organizational Citizenship Behavior: A Study of Public Sector Organizations in Western Province, Sri Lanka
}

\author{
H. M. S. V. Silva ${ }^{1}$ and K. P. W. C. Madhumali ${ }^{2}$ \\ ${ }^{1,2}$ Department of Human Resource Management, University of Kelaniya, Sri Lanka \\ ${ }^{1}$ michellevindya@kln.ac.lk, ${ }^{2}$ chamithramadhumali@gmail.com
}

\begin{abstract}
Although, the study of organizational justice has increased markedly in the past few years, little work has focused on the impact of justice perceptions on organizational citizenship behaviour. This study examines the impact from perceptions of fairness on organizational citizenship behaviors in 102 sample drawn from four public sector organizations in western province, Sri Lanka. A theoretical basis for a relationship between fairness and citizenship was drawn from equity theory and other theories of social exchange. Findings of the study revealed that that there is an impact from distribute, procedural and interactional justice on employee citizenship behavior and further, as a whole there is a significant impact from Organizational justice on Employee citizenship behaviour.
\end{abstract}

Keywords: Distribute Justice, Procedural Justice, Interactional Justice, Organizational Justice, Employee Citizenship Behavior

\section{Introduction}

In reviewing literature on organizational justice, Greenberg (1990) suggested that organizational justice research may theoretically explain many organizational behavior outcome variables. Organizational justice is the term used to describe the role of fairness in workplace. Specifically, organizational justice is concerned with the ways in which employees determine if they have been treated fairly in their jobs and the ways in which those determinations influence other work-related variables (Moorman, 1991). Organizational justice describes the individual's and the group's perception of the fairness of treatment received from an 
organization and their behavioral reaction to such perceptions (James,1993).Three main proposed components of organizational justice are distributive, procedural, and interactional justice (which includes informational and interpersonal justice). Distributive, procedural, and interactional justices are correlated. They can be meaningfully treated as three components of overall fairness (Ambrose \& Arnaud, 2005; Ambrose $\&$ Schminke, 2007), and the three components can work together.

Distributive justice is conceptualized as the fairness associated with decision outcomes and distribution of resources. The outcomes or resources distributed may be tangible (e.g., pay) or intangible (e.g., praise). Perceptions of distributive justice can be fostered when outcomes are perceived to be equally applied (Ambrose \& Arnaud, 2005). Distributive justice relates to people's perceptions of the fairness of the outcomes they receive relative to their contributions and to the outcomes and contributions of others (Folger \& Greenberg, 1985).

Procedural justice is defined as the fairness of the processes that lead to outcomes. When individuals feel that they have a voice in the process or that the process involves characteristics such as consistency, accuracy, ethicality, and lack of bias then procedural justice is enhanced (Butler, 2012). Interactional justice refers to the treatment that an individual receives as decisions are made and can be promoted by providing explanations for decisions and delivering the news with sensitivity and respect. 'A construct validation study by Colquitt (2001) suggests that interactional justice should be broken into two components: interpersonal and informational justice. Interpersonal justice refers to perceptions of respect and propriety in one's treatment. Informational justice focuses on explanations provided to people that convey information about why procedures were used in a certain way or why outcomes were distributed in a certain fashion. Informational justice related to the adequacy of the explanations given in terms of their timeliness, specificity, and truthfulness. In essence, the value of organizational justice is that if employees believe that they are treated justly, they will be more likely to hold positive attitudes about their work, their work outcomes, and their supervisors. Both early and more recent work on equity theory (Adams, 1965; Greenberg, 
1989) has shown that employee job performance may vary in relation to perceptions of inequitable outcomes.

However, because job performance is often heavily influenced by situational contingencies, finding an effect of employee attitudes like perceptions of fairness has been difficult. In addition, unorthodox or nontraditional types of job behavior is largely found in the relationship between perceptions of fairness and employee behavior. These non-traditional behaviors are on-the-job behaviors that are not usually captured by traditional job descriptions and thus are more likely to be under personal control. One such example of nontraditional job behavior is organizational citizenship behavior (OCB). OCBs are explained as work-related behaviors that are discretionary, not related to the formal organizational reward system, and, in the aggregate, promote the effective functioning of the organization (Organ, 1988). Organ has suggested that OCB should be considered an important component of job performance because citizenship behaviors are part of the natural and innovative behaviors noted by Katz and Kahn (1966) as being instrumental for effective organizations. Organ (1988) proposed that the cognitive component of job satisfaction that appears to be related to OCB probably reflects the influence of perceptions of fairness. OCB is explained as "individual behavior that is discretionary, not directly or explicitly recognized by the formal reward system, and that in the aggregate promotes the effective functioning of the organization" (Organ, 1988). Organ's (1988) five-component model of citizenship behavior is one of the most well recognized and influential taxonomies in the literature (LePine, Erez \&Johnson, 2002). This model emphasizes different ways in which employees can demonstrate citizenship behavior. These five components of OCB consist with Altruism, Courtesy, Sportsmanship, Conscientiousness and Civic Virtue. In his recent work, Organ (1988) suggested that OCB could be considered as an input for one's equity ratio and that raising or lowering one's level of OCB. In summary, the studies by Greenberg (1990), Moorman (1991), Folger and Greenberg, (1985), Adams (1965), Greenberg (1989) and Organ, (1988) provide support for a relationship between perceptions of fairness and OCB.

In addition, scholars hypothesized that there is a significant difference in the degree of OCB of employees in public sector and private sector 
organizations (Houston, 2000). Further, it is generally believed that public employees are motivated by a sense of service not found among private employees (Houston, 2000). Public employees in government organizations are seen as motivated by a concern for the community and a desire to serve the public interest, and are more likely to be characterized by an ethic that prioritizes intrinsic rewards over extrinsic rewards (Crewson, 1997). We can guess that public employees will place a high value on institutional justice (organizational justice) and pro-social job behavior such as organizational citizenship behavior (OCB). However, there are only a few studies to examine the effect of public service perception of fairness on their OCB (Kim, 2006). In recent times most of the people give considerable attention to organizational justice and organizational citizenship behavior to gain competitive advantage from the environment. In Sri Lanka only few studies relate to organizational justice and organizational citizenship behavior considering public sector organizations. Thus, the purpose of this study is to test the impact of perceptions of organizational justice (in the form of distributive justice, procedural justice $\&$ interactional justice) on citizenship behavior of employees those who work in well reputed public sector organizations in Sri Lanka. In order to achieve above purpose, researcher has developed four hypotheses with the aid of literature as follows.

$\mathbf{H}_{1}$ : There is an impact from interactional justice on OCB.

$\mathbf{H}_{2}$ : There is an impact from organizational justice on OCB.

$\mathbf{H}_{3}$ : There is an impact from distributive justice on OCB.

$\mathbf{H}_{4}$ : There is an impact from procedural justice on OCB.

Based on above four hypotheses, the conceptual framework of the study is as follows. 


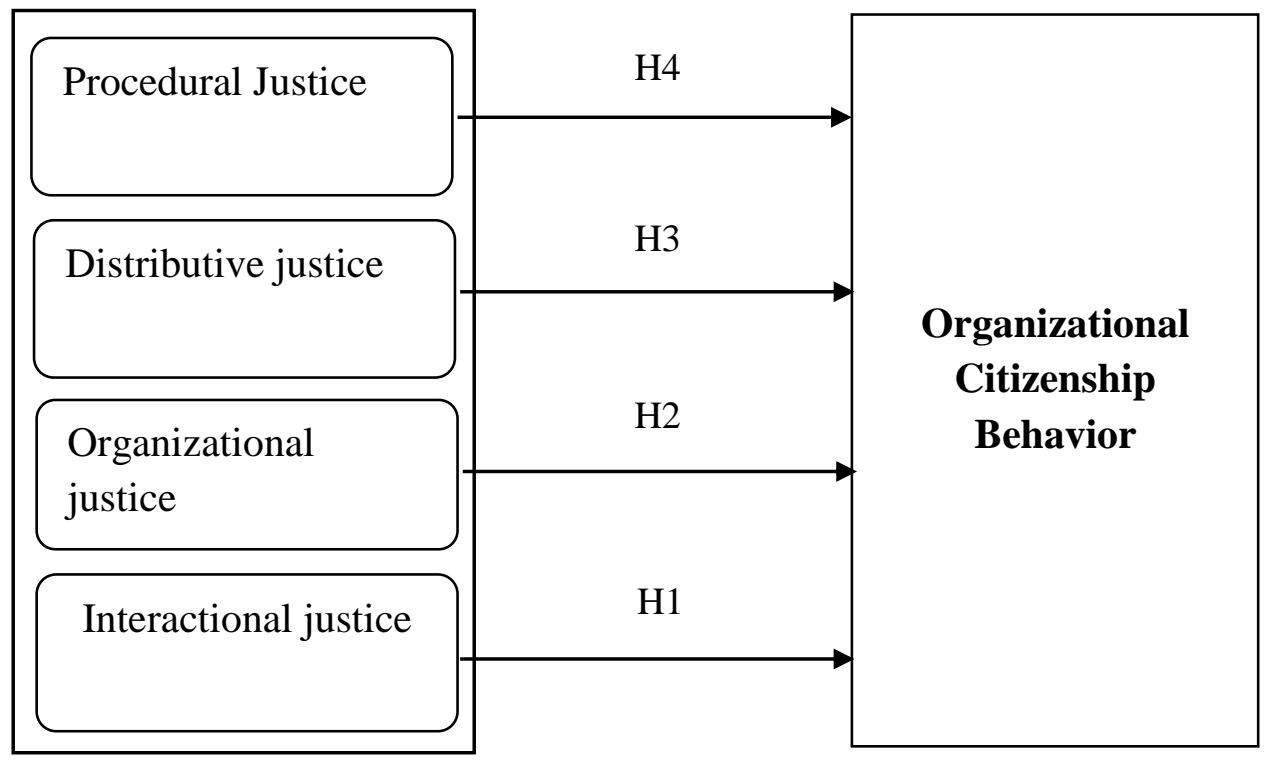

Figure 01: Relationships between organizational justice and organizational Citizenship

\section{Methods and Materials}

As the research context, researcher has selected four public sector organizations in Western Province Sri Lanka. They are, Ceylon Petroleum Corporation, Ceylon Electricity Board, Ceylon Transport Board and The Ministry of Child Development and Women's Affairs (MCDWA) in western province in Sri Lanka. This was cross-sectional study since data was collected in a particular point of time and it did not repeat. Accordingly, survey strategy was followed and self- administered questionnaire was used as the data collection instrument. Organizational justice was measured using the Supervisor-Focused, Multiple Event-Based Adaptation Measure developed by Colquitt (2001). Further, OCBs were measured with the Organizational Citizenship Behavior Scale, recently developed by Podsakoff and MacKenzie (1989). In addition, pilot test was conducted prior to the distribution of the final version of the questionnaire to target population and respondents were assured that all responses of them would be strictly anonymous and encouraged them to answer the questions as 
truthfully as possible. The potential respondents of this study are executives, clerks and other clerical level employees who currently working in aforementioned companies. This study has used the convenience sampling technique to select direct supervisors and final pre- tested questionnaire was distributed among 150 direct supervisors and received only 108 in return. But out of the received questionnaires, only 102 were usable since other two had high missing values. The response rate was $72 \%$ and which was acceptable.

\section{Data analyses and Presentation}

\subsection{Demographic Information}

According to the survey data, $32 \%$ employees were in executive level position and other $68 \%$ were in clerical level. Age composition of the sample showed that, most (31\%) are in category 30-40 years. In addition, $59 \%$ of the respondents were female while $41 \%$ were males. Further, $81 \%$ of the respondents were married and other $19 \%$ were unmarried. According to the demographic data $16 \%$ of the respondents have been passed the G.C.E.O/L exam, and only $3 \%$ obtained post graduate qualification. Moreover, only $2 \%$ of respondents were completed professional courses relevant for their careers. When pay attention on job experience at the current organization, only $17 \%$ of respondents were having less than 5 years of experience and majority (32\%) were having 5-15 years' experience. According to the survey results, Most (36\%) respondents were currently receiving salary in between Rs.20,000 to Rs.30,000 and only 5\% were enjoying in between Rs.40,000 to Rs.50,000 which is the highest salary range.

\subsection{Preliminary Analyses}

With regard to the normality of data, Kline (2005) established a rule of thumb for skew index of absolute value less than 03 and kurtosis value less than 10 was used to test the normality of the data distribution. Accordingly, results indicates that the sample data is normally distributed and data transformations available to address problems of normality in non -normal distribution as stated by Hair et al., (2010) are not required for this study. Scatter plot diagram and residual plots were drawn to examine linearity 
between variables. In scatter diagrams, scatter plots took an approximately oval shape according to the visual inspection. Further, 'Lack of fit' test was also performed on data to further confirm linearity. In the lack of fit test, the probability of the $\mathrm{F}$ test statistic $(\mathrm{F}=1.817)$ was 0.068 , which is greater than the alpha level of significance of 0.05 . Thus, the null hypothesis that "a linear regression model is appropriate" is not rejected. Thus, it confirmed that that linearity assumption was met. With regard to content validity, confirmatory factor analysis was performed with the aid of AMOS to assess the validity of the instruments. As all two variables are measured with multi dimensions second order confirmatory factor analysis in this study. According to Hair (2010), the standardized factor loading estimates of the measurement model should be .5 or higher and ideally .7 or higher to ensure construct validity. Accordingly, all the standardized regression weights for items in the measures are above .5 and these estimates denote that the indicators are related to the associated variables and approve construct validity in this study.

With regard to the reliability of constructs, Cronbach alpha values of each constructs were used to test the reliability. Accordingly, all values of reliability are greater than 0.7 which show high reliability in measures.

\section{Table 01: Reliability of construct measures}

\begin{tabular}{lcc}
\hline \multicolumn{1}{c}{ Construct Measures } & No of Items & Cronbach's Alpha \\
\hline Distributive Justice & 4 & .771 \\
Procedural Justice & 7 & .883 \\
Interactional Justice & 9 & .931 \\
Organizational Justice & 20 & .932 \\
Organizational Citizenship Behavior & 25 & .857 \\
\hline
\end{tabular}

\section{Source: Survey Data}

In addition, Correlation between organizational justice and OCB is . 371 and it reflects medium positive relationship between two constructs according to the criteria provided by Field (2009). 


\subsection{Hypotheses Testing}

Multiple regression analysis was performed to test the hypotheses of this study. The first, linear regression was performed to test the Impact of organizational justice on organizational citizenship behaviour of clerical and executive employees working at public sector organizations in western province in Sri Lanka.

Table 02: Model parameters of hypotheses - Measuring Impact of organizational justice on organizational citizenship behaviour

\begin{tabular}{llll}
\hline Model & \multicolumn{2}{l}{ Standardized Coefficients } & Sig. \\
& & \\
Organizational Justice & 3.953 & .000
\end{tabular}

a. Dependent Variable: Organizational Citizenship Behavior

Table 03: Model summary of hypotheses - Measuring Impact of organizational justice on organizational citizenship behavior

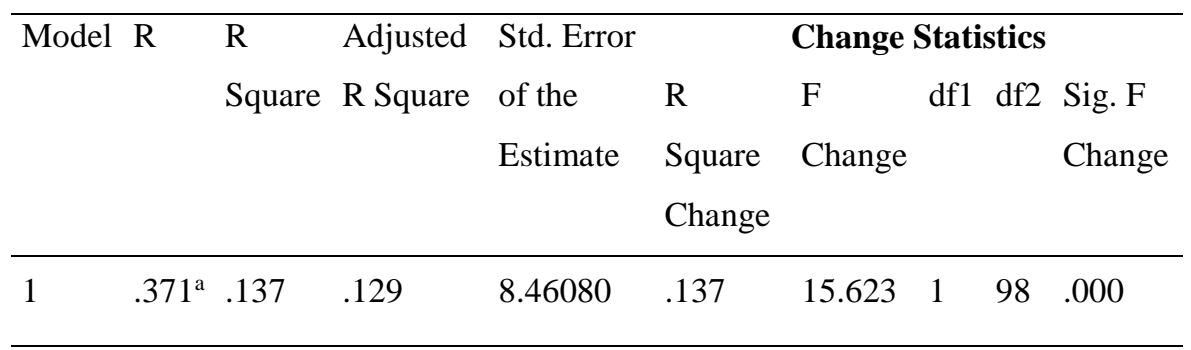

a. Predictors: (Constant), Organizational Justice

\subsection{Model Parameters}

According to Field (2009) the b values give the contribution of each predictor to the model. The standardized beta $(\beta)$ for Organizational justice in Model 01 indicates that there is a positive impact from them on organizational citizenship behaviour of executive and clerical level employees in public sector organizations in western province in Sri Lanka, and it means that when organizational justice increases by one standard 
deviation, organizational citizenship behaviour increases by .371. "The smaller the value of Sig. (and the larger the value of $t$ ), the greater the contribution of that predictor" (Field, 2009, p. 239). Accordingly, the probability of the $t$-statistic for the standardized beta $(\beta)$ coefficient of Organizational justice is significant at .00 which is less than the level of .05 .

\subsection{Model Summary}

The model 1 indicates that $13.7 \%$ of the variance in organizational citizenship behaviour of executive and clerical level employees in public sector organizations in western province in Sri Lanka is explained by organizational justice alone. $F$ statistic indicates the significance of $R 2$ and as the $\mathrm{f}$ change significant at .05 level, it can be concluded that the addition of organizational justice has increased the predictability of the model significantly. According to the output of this study, the first hypothesis was supported and it can be concluded that, there is a positive impact from organizational justice on OCB.

The figures in Table 4 indicate that the tolerance is far greater than .1 (Field, 2009) and the VIF is far less than 10 for each predictor (Myers, as cited in Field, 2009). These values in table 4 reveals that no multicollinearity between dimensions of organizational justice and assure that remedial actions are not required as well. 
Table 04: Model parameters of hypotheses - Measuring Impact of organizational justice on organizational citizenship behaviour

\begin{tabular}{|c|c|c|c|c|c|}
\hline \multirow[t]{2}{*}{ Model } & \multirow{2}{*}{$\begin{array}{l}\text { Standardized } \\
\text { Coefficients } \\
\text { Beta }\end{array}$} & \multirow[t]{2}{*}{$\mathrm{t}$} & \multirow[t]{2}{*}{ Sig. } & \multicolumn{2}{|c|}{$\begin{array}{l}\text { Collinearity } \\
\text { Statistics }\end{array}$} \\
\hline & & & & Tolerance & VIF \\
\hline $\begin{array}{l}\text { Distributive } \\
\text { Justice }\end{array}$ & .201 & 9.008 & .033 & .617 & 1.620 \\
\hline $\begin{array}{l}\text { Procedural } \\
\text { Justice }\end{array}$ & .338 & 8.765 & .046 & .272 & 3.679 \\
\hline $\begin{array}{l}\text { Interactional } \\
\text { Justice }\end{array}$ & .467 & 10.563 & .021 & .304 & 3.287 \\
\hline
\end{tabular}

Source: Survey Data, 2015

The standardized beta $(\beta)$ for distributive, procedural and interactional justice indicate that there are positive impact from them on organizational citizenship behaviour of executive and clerical level employees in public sector organizations in western province in Sri Lanka, and it means that when distributive, procedural and interactional justice increases by one standard deviation, organizational citizenship behaviour increases by .201, $.338, .467$ respectively. Accordingly, the probability of the $t$-statistic for the standardized beta $(\beta)$ coefficients of Distributive, Procedural and Interactional justice are significant at .00 which is less than the level of .05.Thus, the results of table 4 reveals that there is a positive impact from distributive, procedural and interactional justice on organizational citizenship behaviour of executive and clerical level employees in public sector organizations in western province in Sri Lanka. Thus finally, the first three hypotheses were also supported.

\section{Limitations of the Study}

Researcher has experienced a number of limitations during this study. The first limitation was that the researcher did not have direct access to a survey population. The constitution of the survey population may not have been ideal. Due to the limited access to a survey population and unknown 
population size, this study was limited to smaller survey population. Thus, the survey population was limited to 102 respondents.

The risk of response bias is a legitimate risk factor when any research is being conducted. Respondents often feel the need to provide socially desirable answers in order to avoid bringing notice to themselves. Even though this limitation is common for any research, researcher has developed a survey to overcome it, in which all participants responses remained completely anonymous and the survey did not request any personal information.

The next limitation is inability to conduct a longitudinal study for this research. Because the nature of this study is to demonstrate impact from one variable on another variable, it is more meaningful if the study is carried out time to time as a longitudinal study. But due to limitations in time, the researcher was restricted to a short time frame and limited resources, a longitudinal study was not feasible in this study. In addition, this study has used only data from clerical and executive employees and used only questionnaire method to collect data, there is a probability of CMV to occur.

Quantitative research usually uses probability sampling techniques to guarantee generalization (Saunders et al, 2012). Due to the practical constraint like unknown population size, convenience sampling technique was adopted which is a non - probability sampling method. Moreover use both questionnaires and interviews as data collection methods, this study will able to draw a very representative and meaningful picture about the entire population than now.

\section{Directions for Future Research}

This study was conducted only considering four public sector organizations in Western Province. Future studies could be expanded to whole public sector organizations or it can be done in the other eight provinces as well. This kind of research could be expanded to other manufacturing private organizations in Sri Lanka. The sample consisted only of executive and clerical level employees in four selected organizations. Future research on this area can be done considering more representative sample consisting of managerial level employees or operational level employees or knowledge workers. The sample size of this study is 102 , it can be recommended to do 
research in future on this topic with a larger sample size to draw a more representative picture. In addition, the predictor variable of this study was only organizational justice it could be recommended to use other predictor variables like Impression Management, Organizational Commitment, Reward management, Job Involvement for Organizational citizenship behaviour. Finally, researcher can recommend to use intervening variables like trust in organization, trust in supervisor in between organizational justice and organizational citizenship behaviour of employees for future studies.

\section{Conclusion}

This research attempted to show that perceptions of fairness influence employees' decisions to behave as organizational citizens. The results indicate that fairness perceptions, particularly those derived from distributive and procedural and interactional justice, are instrumental in predicting the occurrence of citizenship. Therefore, managers should be aware of the benefits of behaving toward subordinates in a manner perceived as fair. Managers should pay high attention on how they treat their employees because employees' perceptions of that handling could affect the occurrence of citizenship behaviors.

\section{References}

Adams, J. S. (1965). Inequity in social exchange. Advances in experimental social psychology, 2, 267-299. Retrieved from http://dx.doi.org/10.1016/S0065-2601(08)60108-2

Ambrose, M. L., \& Schminke, M. (2007). Examining justice climate: Issues of fit, simplicity, and content. Research in multilevel issues, 6, 397413.

Ambrose, M. L., Arnaud, A., Greenberg, J., \& Colquitt, J. (2005). Distributive and procedural justice: Construct distinctiveness, construct interdependence, and overall justice. The handbook of organizational justice, 59-84. 
Kelaniya Journal of Human Resource Management

Volume 09-Number 01-January 2014 \& Number 02-July 2014

Butler, A. (2012). The effects of organizational justice perceptions associated with the use of electronic monitoring on employees' organizational citizenship and withdrawal behaviours: A social exchange perspective.

Colquitt, J. A. (2001). On the dimensionality of organizational justice: a construct validation of a measure. Journal of applied psychology, 86(3), 386-400. Retrieved from http://dx.doi.org/10.1037/0021-9010.86.3.386

Crewson, P. E. (1997). Public-service motivation: Building empirical evidence of incidence and effect. Journal of public administration research and theory, 7(4), 499-518.

Field, A. (2009). Discovering statistics using SPSS. Sage publications.

Folger, R., \& Greenberg, J. (1985). Procedural justice: An interpretive analysis of personnel systems. Research in personnel and human resources management, 3(141-183).

Greenberg, J. (1986). Determinants of perceived fairness of performance evaluations. Journal of applied psychology, 71(2), 340-342. Retrieved from http://dx.doi.org/10.1037/0021-9010.71.2.340

Greenberg, J. (1990). Organizational justice: Yesterday, today, and tomorrow. Journal of management, 16(2), 399-432.

DOI: $10.1177 / 014920639001600208$

Hair, J. F. (2010). Multivariate data analysis. Pearson College Division.

Houston, D. J. (2000). Public-service motivation: A multivariate test. Journal of public administration research and theory, 10(4), 713-728.

Katz, D., \& Kahn, R. L. (1966). The psychology of organizations. New York: HR Folks International.

Kline, T. J. (2005). Psychological testing: A practical approach to design and evaluation. Sage Publications. 
Kelaniya Journal of Human Resource Management

Volume 09-Number 01-January 2014 \& Number 02-July 2014

LePine, J. A., Erez, A., \& Johnson, D. E. (2002). The nature and dimensionality of organizational citizenship behavior: a critical review and meta-analysis. Journal of applied psychology, 87(1), 5265. Retrieved form http://dx.doi.org/10.1037/0021-9010.87.1.52

Organ, D. W. (1988). Organizational citizenship behavior: The good soldier syndrome. Lexington Books/DC Heath and Com.

Podsakoff, P. M., \& MacKenzie, S. B. (1989). A second generation measure of organizational citizenship behavior. Unpublished manuscript, Indiana University, Bloomington. 